\title{
Mothers' intention to vaccinate their daughter against human papillomavirus in Taiwan
}

\author{
Shu-Ling Chen ${ }^{1}$, Fu-Hsuan Chen ${ }^{1}$, Mon-Fa Lin ${ }^{1}$, Cheng-I Yang ${ }^{* 2}$ \\ ${ }^{1}$ Department of Nursing, Hungkuang University, Taichung, Taiwan \\ ${ }^{2}$ Department of Nursing, DaYeh University, Changhua, Taiwan
}

Received: July 25, 2016

DOI: $10.5430 /$ ijh.v2n2p81
Accepted: August 31, 2016

Online Published: September 18, 2016

\begin{abstract}
The uptake of HPV vaccination is $<10 \%$ in Taiwan and little is known about mothers' intention to vaccinate daughters against HPV. The aims of this study were to explore mothers' reasons for and against vaccinating their daughters against HPV. A total of 511 women were obtained from a regional hospital in central Taiwan. Descriptive analysis and multivariate logistic regression were employed. The authors found the most frequent reason given by mothers for not vaccinating their daughters was "vaccination price is too high". Mothers with high intention to vaccinate their daughters were more likely than low-intention mothers to believe that HPV vaccination is safe and effective and to accept recommendations from others and the media. When mothers were asked whether they were willing to pay for vaccinating their daughter if HPV vaccination were not free, the percentage of high-intention mothers dropped from $88.9 \%$ to $69.8 \%$, and the percentage of low-intention mothers dropped precipitously from $60.2 \%$ to $17.9 \%$. Findings can be used by policy makers in Taiwan to plan appropriate activities and strategies to encourage mothers to have daughters receive the HPV vaccine.
\end{abstract}

Key Words: Human papillomavirus, Vaccine, Mothers, Daughters, Intention

\section{INTRODUCTION}

Cervical cancer is the second cause of female cancer mortality in Asia as well as worldwide. ${ }^{[1]}$ While comprehensive screening by Pap exam has decreased the mortality from cervical cancer among Taiwanese women over the last 20 years, cervical cancer is still the seventh leading cancer in women. ${ }^{[2]}$ Among 2,175 million Taiwanese women over age 30 who received Pap exams in 2013, pre-cancer was detected in 9,996 and cancer in 4,191. ${ }^{[2]}$ Cervical cancer has been linked to human papilloma virus (HPV), and HPV vaccination is most effective against cervical cancer in women if they receive it before they become sexually active and are exposed to HPV.$^{[3,4]}$ Thus, HPV vaccines are recommended for adolescent girls to prevent cervical cancer (Gardasil ${ }^{\circledR}$ and Cervarix ${ }^{\mathrm{TM}}$ ) and genital warts (Gardasil $\left.{ }^{\circledR}\right) .{ }^{[5,6]}$ Vaccination with Gardasil ${ }^{\mathrm{R}}$ (quadrivalent human papillomavirus recombinant vaccine) was $90 \%$ to $100 \%$ effective in preventing precancerous cervical, vaginal, and vulvar lesions and genital warts, which were caused by infection with the relevant HPV types $(6,11,16$, or 18) in women aged 15 to 26 years who were uninfected prior to vaccination. ${ }^{[7-9]}$ Romanowski et al. (2009) findings show excellent long-term efficacy, high and sustained immunogenicity, and favorable safety of the HPV-16/18 AS04-adjuvanted vaccine up to 6.4 years. ${ }^{[9]}$ In 2014, CDC published a report analyzing health events reported to VAERS (Vaccine Adverse Event Report-

*Correspondence: Cheng-I Yang, PhD; Email: arcoyang@mail2000.com; Address: No.168, University Rd., Dacun, Changhua 51591, Taiwan(R.O.C.). 
ing System) following Gardasil vaccination from June 2006 through March 2014. About $92 \%$ of the Gardasil reports were classified as non-serious. The most common adverse events reported were syncope (fainting), dizziness, nausea, headache, fever, and injection site reactions (pain, swelling, and redness). ${ }^{[10,11]}$ In Taiwan, the most common adverse events were swelling and redness at the injection site, rash, mild fever, headache, and dizziness. ${ }^{[2]}$

These two HPV vaccines, Gardasil ${ }^{\circledR}$ and Cervarix ${ }^{\mathrm{TM}}$ were approved by Taiwan in 2006 and 2008, respectively. ${ }^{[2,12,13]}$ Both HPV vaccines are administered as a 3 -dose series. ${ }^{[5]}$ The first vaccination injection is followed by a second injection 1-2 months later, and the third injection 6 months after the first one. ${ }^{[5]}$ A 3-dose series of HPV vaccination costs 12,000 New Taiwan dollars (NTD) (approximately US\$375), ${ }^{[14]}$ whereas a suggested fair price for HPV vaccination in Taiwan is 500 NTD (approximately US\$16). ${ }^{[15]}$ The recommended age ranges for HPV vaccination in Taiwan are 9-26 years for Gardasil and 10-25 years for Cervarix. ${ }^{[12,13]}$ Because HPV vaccination is not covered by Taiwan's national health insurance, we considered that one hurdle for mothers' acceptance of vaccinating a daughter against HPV would be the high cost of vaccination as suggested for Taiwan ${ }^{[16]}$ and reported in Hong Kong ${ }^{[17]}$ and Morocco. ${ }^{[18]}$ Considering that adolescent girls are at the optimum age for HPV vaccination to prevent cervical cancer, five of 13 counties in Taiwan have started providing HPV vaccination free of charge to female teenage students. ${ }^{[12,19]}$

Since parents play an important role in the decision to vaccinate a daughter against $\mathrm{HPV},{ }^{[20,21]}$ their health-related beliefs and experiences regarding HPV will influence whether the daughter is vaccinated. ${ }^{[21,22]}$ For example, US mothers' decisions to vaccinate their daughters were influenced by their belief in the benefit of HPV vaccination ${ }^{[20,21]}$ and exposure to media and marketing regarding HPV vaccines, especially television commercials. ${ }^{[21]}$ Media such as web sites/the Internet and news stories ${ }^{[23]}$ as well as perceived beliefs of significant others ${ }^{[22]}$ and drug company advertising ${ }^{[24]}$ may improve parents' beliefs and knowledge about HPV vaccine. In addition, physician recommendations play a significant role in parents' decision to vaccinate their daughters against HPV; ${ }^{[22-25]}$ However, the uptake of HPV vaccination is less than $10 \%$ in Taiwan ${ }^{[26]}$ and little is known about mothers' intention to vaccinate daughters against HPV. Because the vaccine manufacturer's media-information campaign has targeted mothers in Taiwan.

The aim of the current study was to explore mothers' reasons for and against vaccinating their daughters against HPV as well as associations between their intention to vaccinate their daughters and beliefs about HPV vaccination, influence by others' and media recommendations, and HPV vaccination cost considerations.

\section{METHOD}

\subsection{Sample and procedures}

A convenience sample was recruited from mothers attending a regional hospital in central Taiwan and having at least one daughter 9-26 years old. This age range was chosen because it represents girls and women for whom the quadrivalent vaccine is licensed in Taiwan. ${ }^{[12,13]}$

\subsection{Measures}

Data were collected from mothers by questionnaire on three categories of variables: demographic characteristics, including whether or not daughter(s) had received HPV vaccine, reasons for or against vaccinating their daughters, and beliefs, intention, sources of influence, and cost considerations about HPV vaccination. Questions for the second and third categories of variables were developed based on the relevant literature, as included (1) reasons for or against (unwillingness to vaccinate) vaccinating daughters were adapted from a published list. ${ }^{[27]}$ Mothers were allowed to choose/give more than one reason for non-vaccination; (2) beliefs about the HPV vaccine were assessed by two items: "the HPV vaccine is safe," and "the HPV vaccine effectively prevents cervical cancer." Responses can range from 1 (strongly disagree) to 5 (strongly agree). ${ }^{[28]}$ Cronbach's alpha in this study was 0.80 ; (3) intention was assessed with the single item: "I am willing to vaccinate my daughter against HPV." Responses can range from 1 (strongly disagree) to 5 (strongly agree). A single item to measure intention is supported by previous HPV research ${ }^{[29]}$ as a reliable and valid measure of intention.

\subsection{Statistical analysis}

Data were analyzed by descriptive statistics and the chisquare test using SPSS version 21.0 for Windows (SPSS Inc., Chicago, IL). Chi-square tests were used to examine the associations between intention to vaccinate daughters and beliefs about the HPV vaccine; influence by recommendations from others, the media, and Internet; and HPV vaccination cost considerations. Multivariate logistic regression analysis was used to determined predictors of mothers' intention to vaccinate their daughters.

\subsection{Ethical Approval}

This study was approved by the Jen-Ai Hospital's Institutional Review Board (No: 100-11). Data were collected between December 2011 and January 2012 by the second author who explained the study purpose and assured participants' anonymity and confidentiality of responses. Those 
who agreed to participate signed informed consent and were given a small gift (a cash coupon worth 100 NTD [approximately US\$3]).

\section{Results}

\section{Sample characteristics}

The sample of 511 mothers had a mean age of 45.25 years $(S D=5.95)$, with the majority in the $40-49$ year age bracket $(53.6 \%)$ and having < a high school education $(58.1 \%$; see Table 1). The largest proportion of mothers had a monthly household income of 20,000 to 40,000 NTD (48.5\%), and only $22.7 \%$ of mothers had a family history of gynecologic cancer. The majority of mothers had one daughter $<26$ years old $(66.9 \%)$ and only 38 mothers' daughters had received the HPV vaccine (7.4\%). For details, see Table 1.

Table 1. Sample characteristics $(\mathrm{N}=511)$

\begin{tabular}{|c|c|c|c|c|}
\hline Characteristic & Mean & $\overline{S D}$ & $\bar{n}$ & $\%$ \\
\hline Age, years & 45.25 & 5.95 & & \\
\hline$\leq 29$ & & & 4 & 0.8 \\
\hline $30-39$ & & & 90 & 17.6 \\
\hline $40-49$ & & & 274 & 53.6 \\
\hline$\geq 50$ & & & 143 & 28.0 \\
\hline \multicolumn{5}{|l|}{ Education } \\
\hline$\leq$ High school & & & 297 & 58.1 \\
\hline College & & & 96 & 18.8 \\
\hline Baccalaureate degree & & & 98 & 19.2 \\
\hline$\geq$ Graduate degree & & & 20 & 3.9 \\
\hline \multicolumn{5}{|c|}{ Household income (NTD per month) } \\
\hline$<20,000$ & & & 150 & 29.4 \\
\hline $20,000-40,000$ & & & 248 & 48.5 \\
\hline $40,000-60,000$ & & & 58 & 11.3 \\
\hline$\geq 60,000$ & & & 55 & 10.8 \\
\hline \multicolumn{5}{|c|}{ Family history of gynecologic cancer } \\
\hline Yes & & & 116 & 22.7 \\
\hline No & & & 395 & 77.3 \\
\hline \multicolumn{5}{|c|}{ Number of daughters $\leq 26$ years } \\
\hline 1 & & & 342 & 66.9 \\
\hline$>1$ & & & 169 & 33.1 \\
\hline \multicolumn{5}{|c|}{ Daughters received HPV vaccine } \\
\hline Yes & & & 38 & 7.4 \\
\hline No & & & 473 & 92.6 \\
\hline
\end{tabular}

Among the 473 mothers who had not vaccinated their daughters against HPV, the most frequent reason for nonvaccination was "Vaccination price is too high $(\mathrm{n}=179$, $37.8 \%$ )," followed by "Do not understand HPV vaccine" $(\mathrm{n}=170,35.9 \%)($ see Table 2$)$. The third most frequent reason was "Unsure if vaccine will work because it is new" $(\mathrm{n}=133,28.1 \%)$. The least frequent reason was "Could not find place to vaccinate" (1.7\%). For details, see Table 2.

Of the 38 mothers who had their daughters vaccinated against HPV, the majority had one daughter (63.2\%), and the largest proportion had their daughters vaccinated at 21-26 years old
(44.7\%). The most frequent reason for choosing to vaccinate their daughters was "HPV vaccine effectively prevents cervical cancer" $(\mathrm{n}=35,92.1 \%)$. For details, see Table 3 .

Table 2. Mothers' reasons for not vaccinating their daughters $(n=473)$

\begin{tabular}{cll}
\hline No. & Reason & $\mathbf{n ( \% )} \mathbf{~}^{\S}$ \\
\hline 1 & Vaccine price is too high & $179(37.8)$ \\
2 & Do not understand information about HPV vaccine & $170(35.9)$ \\
3 & Unsure if vaccine will work because it is new & $133(28.1)$ \\
4 & Afraid of potential side effects & $116(24.5)$ \\
5 & No information about HPV vaccination & $89(18.8)$ \\
6 & Other & $79(16.7)$ \\
7 & The vaccine will encourage sexual activity & $10(2.1)$ \\
8 & Could not find place to vaccinate & $8(1.7)$ \\
\hline Note. ${ }^{\S}$ Total n may exceed 473 as mothers could choose/give more than one reason.
\end{tabular}

Table 3. Mothers' reasons for vaccinating their daughters $(\mathrm{n}=38)$

\begin{tabular}{lc}
\hline Item & $\boldsymbol{n}(\mathbf{\%})^{\S}$ \\
\hline Number of daughters & $24(63.2)$ \\
1 & $11(28.9)$ \\
2 & $3(7.9)$ \\
3 & \\
Daughter's age when vaccinated, years & $9(23.7)$ \\
$11-15$ & $12(31.6)$ \\
$16-20$ & $17(44.7)$ \\
$21-26$ & \\
Mothers' reasons for vaccinating their daughters & $35(92.1)$ \\
HPV vaccine is effective in preventing cervical cancer & $12(31.6)$ \\
HPV vaccine is safe & $4(10.5)$ \\
Other & \\
\hline Note. ${ }^{\S}$ Total n may exceed 38 as mothers could choose/give more than one reason.
\end{tabular}

Mothers whose daughters had not been vaccinated against HPV $(n=473)$ were categorized as high intention to vaccinate their daughters if they rated 4-5 (agree-strongly agree) on the item asking if they intended to have their daughter vaccinated against HPV. Mothers whose daughters had been vaccinated $(\mathrm{n}=38)$ were not included in this analysis. Mothers with high intention $(\mathrm{n}=199,42.1 \%)$ and those with low intention $(\mathrm{n}=274,57.9 \%)$ were compared by chi-square test in terms of beliefs about HPV vaccination, influence by others' or media recommendations to have their daughter vaccinated, and HPV vaccination cost considerations.

As shown in Table 4, the two groups of mothers did not differ in age, education, and number of daughters $<26$ years old. However, high- and low-intention mothers differed significantly by monthly household income and family history of gynecologic cancer. More high-intention mothers had a monthly household income between 20,000 and 40,000 NTD than low-intention mothers $\left(\chi^{2}=23.22, p<.001\right)$. More low-intention mothers had no family history of gynecologic cancer than high-intention mothers $\left(\chi^{2}=6.07, p<.05\right)$. 
Table 4. Variables associated with mothers' intention to vaccinate their daughters

\begin{tabular}{|c|c|c|c|}
\hline \multirow[t]{2}{*}{ Variable } & $\begin{array}{l}\text { High intention } \\
n=199(42.1 \%)\end{array}$ & $\begin{array}{c}\text { Low intention } \\
n=274(57.9 \%)\end{array}$ & \multirow[t]{2}{*}{$p$} \\
\hline & $n(\%)$ & $n(\%)$ & \\
\hline Age, years & & & .773 \\
\hline$\leq 29$ & $1(0.5)$ & $3(1.1)$ & \\
\hline 30-39 & $37(18.6)$ & $52(19.0)$ & \\
\hline $40-49$ & $112(56.3)$ & $144(52.6)$ & \\
\hline$\geq 50$ & 49 (24.6) & $75(27.4)$ & \\
\hline Education & & & .905 \\
\hline$\leq$ High school & $112(56.3)$ & $159(58.1)$ & \\
\hline College & $38(19.1)$ & $53(19.3)$ & \\
\hline Baccalaureate degree & $40(20.1)$ & $53(19.3)$ & \\
\hline$\geq$ Graduate degree & $9(4.5)$ & $9(3.3)$ & \\
\hline Household income (NTD per month) & & & $<.001$ \\
\hline$<20,000$ & $35(17.6)$ & $102(37.2)$ & \\
\hline $20,000-40,0000$ & $116(58.3)$ & $112(40.9)$ & \\
\hline $40,000-60,000$ & $26(13.1)$ & $29(10.6)$ & \\
\hline$\geq 60,000$ & $22(11.1)$ & $31(11.3)$ & \\
\hline Family history of gynecologic cancer & & & .014 \\
\hline Yes & 57 (28.6) & $52(19.0)$ & \\
\hline No & $142(71.4)$ & $222(81.0)$ & \\
\hline Number of daughters $\leq 26$ years & & & .218 \\
\hline 1 & $140(70.4)$ & $178(65.0)$ & \\
\hline$>1$ & 59 (29.4) & $96(35.0)$ & \\
\hline \multicolumn{4}{|l|}{ Beliefs about HPV vaccination } \\
\hline HPV vaccine is safe & & & $<.001$ \\
\hline 1-2 (strongly disagree-disagree) & $2(1.0)$ & $16(5.8)$ & \\
\hline 3 (neither disagree or agree) & $25(12.6)$ & $143(52.2)$ & \\
\hline 4-5 (agree-strongly agree) & $172(86.4)$ & $115(42.0)$ & \\
\hline HPV vaccine effectively prevents cervical cancer & & & $<.001$ \\
\hline 1-2 (strongly disagree-disagree) & $3(1.5)$ & $9(3.3)$ & \\
\hline 3 (neither disagree or agree) & $24(12.1)$ & $98(35.8)$ & \\
\hline 4-5 (agree-strongly agree) & $172(86.4)$ & $167(60.9)$ & \\
\hline \multicolumn{4}{|l|}{ Influence by another person's recommendation } \\
\hline Family or friend & & & $<.001$ \\
\hline 1-2 (strongly disagree-disagree) & $3(1.5)$ & $36(13.1)$ & \\
\hline 3 (neither disagree-neither agree) & $40(20.1)$ & $128(46.7)$ & \\
\hline 4-5 (agree-strongly agree) & $156(78.4)$ & $110(40.1)$ & \\
\hline Teacher & & & $<0.001$ \\
\hline 1-2 (strongly disagree-disagree) & $7(3.5)$ & $45(16.4)$ & \\
\hline 3 (neither disagree or agree & $47(23.6)$ & $144(52.6)$ & \\
\hline 4-5 (agree-strongly agree) & $145(72.9)$ & $85(31.0)$ & \\
\hline Doctor & & & $<.001$ \\
\hline 1-2 (strongly disagree-disagree) & $3(1.5)$ & $25(9.1)$ & \\
\hline 3 (neither disagree or agree & $36(18.1)$ & $127(46.4)$ & \\
\hline 4-5 (agree-strongly agree) & $160(80.4)$ & $122(44.5)$ & \\
\hline Nurse & & & $<.001$ \\
\hline 1-2 (strongly disagree-disagree) & $2(1.0)$ & $25(9.1)$ & \\
\hline 3 (neither disagree or agree & $36(18.1)$ & $127(46.4)$ & \\
\hline 4-5 (agree-strongly agree) & $161(80.9)$ & $122(44.5)$ & \\
\hline Influence by media recommendation & & & $<.001$ \\
\hline \multicolumn{4}{|l|}{ Poster in hospital } \\
\hline 1-2 (strongly disagree-disagree) & $11(5.5)$ & $40(14.6)$ & \\
\hline 3 (neither disagree or agree & $62(31.2)$ & $149(54.4)$ & \\
\hline 4-5 (agree-strongly agree) & $126(63.3)$ & $85(31.0)$ & \\
\hline Newspaper/magazine & & & $<.001$ \\
\hline 1-2 (strongly disagree-disagree) & $11(5.5)$ & $45(16.4)$ & \\
\hline 3 (neither disagree or agree & $55(27.6)$ & $146(53.3)$ & \\
\hline 4-5 (agree-strongly agree) & $133(66.8)$ & $83(30.3)$ & \\
\hline Internet & & & $<.001$ \\
\hline 1-2 (strongly disagree-disagree) & 25 (12.6) & $69(25.2)$ & \\
\hline 3 (neither disagree or agree & $81(40.7)$ & $150(54.7)$ & \\
\hline 4-5 (agree-strongly agree) & $93(46.7)$ & $55(20.1)$ & \\
\hline \multicolumn{4}{|l|}{ HPV vaccination cost consideration } \\
\hline Would pay oneself to vaccinate & & & $<.001$ \\
\hline 1-2 (strongly disagree-disagree) & $10(5.0)$ & $82(29.9)$ & \\
\hline 3 (neither disagree or agree & $50(25.1)$ & $143(52.2)$ & \\
\hline 4-5 (agree-strongly agree) & $139(69.8)$ & $49(17.9)$ & \\
\hline Would vaccinate if free of charge & & & $<.001$ \\
\hline 1-2 (strongly disagree-disagree) & $0(0.0)$ & $14(5.1)$ & \\
\hline 3 (neither disagree or agree & $22(11.1)$ & $95(34.7)$ & \\
\hline 4-5 (agree-strongly agree) & $177(88.9)$ & $165(60.2)$ & \\
\hline
\end{tabular}


Regarding beliefs about HPV vaccination, high-intention mothers were more likely than low-intention mothers to believe that the HPV vaccine is safe $\left(\chi^{2}=95.60\right.$, $p<.001)$ and effectively prevents cervical cancer $\left(\chi^{2}=37.00\right.$, $p<.001)$. Indeed, most high-intention mothers agreed or strongly agreed that the HPV vaccine is safe $(n=172,86.4 \%)$ and effectively prevents cervical cancer $(\mathrm{n}=172,86.4 \%)$, whereas only $115(42 \%)$ and $167(60.9 \%)$ low-intention mothers agreed or strongly agreed with these beliefs, respectively (see Table 4).

Regarding the influence of another person's recommendation to have their daughters vaccinated against HPV, most high-intention mothers agreed or strongly agreed that they would be influenced by nurses' recommendation ( $\mathrm{n}=161,80.9 \%)$, followed by recommendations from doctors $(n=160,80.4 \%)$, family or friends $(n=156,78.4 \%)$ and teachers $(n=145,72.9 \%)$. However, the minority of low-intention mothers agreed or strongly agreed that they would be influenced by nurses' and doctors' recommendation $(\mathrm{n}=122,44.5 \%)$ to have daughters vaccinated against $\mathrm{HPV}$, followed by recommendations of family or friends $(\mathrm{n}=110,40.1 \%)$ and teachers $(\mathrm{n}=85,31.0 \%)$. Highintention mothers were more likely to agree or strongly agree than low-intention mothers that they would be influenced by recommendations from nurses $\left(\chi^{2}=71.02, p<.001\right)$, doctors $\left(\chi^{2}=62.90, p<.001\right)$, family or friends $\left(\chi^{2}=71.89\right.$, $p<.0001)$, and teachers $\left(\chi^{2}=82.88, p<.001\right)$ (see Table 4$)$.

Regarding the influence of media recommendations to have their daughters vaccinated against HPV, the majority of highintention mothers agreed or strongly agreed that they would be influenced by recommendations from the media $(n=133$, $66.8 \%)$, followed by posters in hospital $(n=126,63.3 \%)$ and the Internet $(n=93,46.7 \%)$. However, the minority of low-intention mothers agreed or strongly agreed that they would be influenced to have their daughters vaccinated against HPV by the recommendation of a hospital poster ( $\mathrm{n}=85,31.0 \%$ ), followed by recommendations from the media $(n=83,30.3 \%)$ and Internet $(n=55,20.1 \%)$. Highintention mothers were more likely than low-intention mothers to agree or strongly agree that they would be influenced by recommendations from the media $\left(\chi^{2}=63.11, p<.001\right)$, hospital posters $\left(\chi^{2}=49.69, p<.001\right)$, and Internet $\left(\chi^{2}=40.08\right.$, $p<.001)$. For details, see Table 4 .

Regarding HPV vaccination cost considerations, the majority of high-intention mothers $(n=139,69.8 \%)$ agreed or strongly agreed that they would pay themselves to have their daughters vaccinated against HPV if the vaccine were not covered by national health insurance or government subsidy, while only a minority of low-intention mothers

Published by Sciedu Press
( $n=49,17.9 \%)$ agreed or strongly agreed to paying themselves. High-intention mothers were more likely than lowintention mothers to pay themselves to have their daughters vaccinated against HPV if the vaccine were not free $\left(\chi^{2}=135.77, p<.001\right)$. If HPV vaccines were free of charge, the majority of high-intention $(n=177,88.9 \%)$ and low-intention $(\mathrm{n}=165,60.2 \%)$ mothers agreed or strongly agreed to having their daughters vaccinated against HPV. However, high-intention mothers were more likely than lowintention mothers to have their daughters vaccinated against HPV if HPV vaccines were free of charge $\left(\chi^{2}=49.32\right.$, $p<.001)$ (see Table 4).

To determine predictors of mothers' intention to vaccinate their daughters, we used multivariate logistic regression analysis with significant associations between intention to vaccinate daughters and beliefs about the HPV vaccine, influence by recommendations from others and the media, and HPV vaccination cost considerations as cutoffs for selecting determinants. In the multivariate logistic regression model, we entered seven variables: household income, family history of gynecologic cancer, beliefs about HPV vaccination, influence by others' recommendation, influence by media recommendation, would pay oneself to vaccinate, would vaccinate if free of charge. As shown in Table 5, the best-fitting model (Hosmer and Lemeshow test, $\chi^{2}=4.566, d f=8$, $p=.803$ ) correctly predicted $57.9 \%$ of the cases. This result implies that the odds of mothers' intention to vaccinate their daughters were related to three independent variables: beliefs about HPV vaccination, influence by others' recommendation, and would pay oneself to vaccinate. For each point increase in beliefs about HPV vaccination, the odds of intending to vaccinate one's daughters increased by $181.0 \%$ (odds ratio $[\mathrm{OR}]=2.810,95 \%$ confidence interval $[\mathrm{CI}]=$ $1.64-4.81, p<.001)$. Likewise, for each point increase in influence by others' recommendation, the odds of intending to vaccinate one's daughters increased by $176.7 \%(\mathrm{OR}=2.767$, $95 \% \mathrm{CI}=1.64-4.66, p<.001)$ (see Table 5 ). For each point increase in paying oneself to vaccinate, the odds of intending to vaccine one's daughters increased by $501.6 \%$ (OR $=6.016$, $95 \% \mathrm{CI}=3.59-10.08, p<.001)$. Finally, predicting mothers' intent to vaccinate their daughters was not significantly associated with household income, family history of gynecologic cancer, and willingness to vaccinate if free of charge (see Table 5).

\section{Discussion}

Among the 511 mother respondents, only 38 (7.4\%) had their daughter receive the HPV vaccines, consistent with a low uptake of HPV vaccines in Taiwan. ${ }^{[26]}$ Moreover, fewer than one-quarter of these mothers' daughters $(23.7 \%)$ were vacci- 
nated between 11 and 15 years old, consistent with survey results from US nurses who had less intention to vaccinate their daughters $<13$ years old than their older daughters. ${ }^{\text {[21] }}$ These findings highlight the need for educational interven- tions to target mothers of teenage daughters to increase the uptake rate of HPV vaccines.

Table 5. Logistic regression analysis for predictors of mothers' intent to vaccinate their daughters $\S$

\begin{tabular}{|c|c|c|}
\hline Variable & $\beta$ & Odds ratio ( $95 \%$ confidence interval) \\
\hline \multicolumn{3}{|c|}{ Household income (NTD per month) } \\
\hline$>40,000$ & 0.23 & $1.26(0.73,2.16)$ \\
\hline$\leq 40,000$ & $1(\mathrm{ref})^{\#}$ & \\
\hline \multicolumn{3}{|c|}{ Family history of gynecologic cancer } \\
\hline Yes & 0.25 & $1.29(0.75,2.21)$ \\
\hline No & 1 (ref) ${ }^{\#}$ & \\
\hline \multicolumn{3}{|l|}{ Beliefs about HPV vaccination } \\
\hline Agree-strongly agree (4-5) & $1.03^{* * *}$ & $2.81(1.64,4.81)$ \\
\hline Strongly disagree-neither (1-3) & $1(\mathrm{ref})^{\#}$ & \\
\hline \multicolumn{3}{|c|}{ Influence by others' recommendation } \\
\hline Agree-strongly agree (4-5) & $1.02^{* * *}$ & $2.77(1.64,4.66)$ \\
\hline Strongly disagree-neither (1-3) & 1 (ref) ${ }^{\#}$ & \\
\hline \multicolumn{3}{|c|}{ Influence by media recommendation } \\
\hline Agree-strongly agree (4-5) & 0.10 & $1.10(0.63,1.92)$ \\
\hline Strongly disagree-neither (1-3) & $1\left(\right.$ ref) ${ }^{\#}$ & \\
\hline \multicolumn{3}{|l|}{ Would pay oneself to vaccinate } \\
\hline Agree-strongly agree (4-5) & $1.79^{* * *}$ & $6.02(3.59,10.08)$ \\
\hline Strongly disagree-neither (1-3) & 1 (ref) ${ }^{\#}$ & \\
\hline \multicolumn{3}{|l|}{ Would vaccinate if free of charge } \\
\hline Agree-strongly agree (4-5) & 0.02 & $1.02(0.55,1.93)$ \\
\hline Strongly disagree-neither (1-3) & 1 (ref) ${ }^{\#}$ & \\
\hline Constant & $-2.41^{* * *}$ & 0.09 \\
\hline
\end{tabular}

Taiwanese mothers whose daughters had not been vaccinated against HPV did not vaccinate their daughters because of the high price of vaccination, lack of HPV knowledge, and concerns about side effects and effectiveness of vaccination, consistent with previous reports. ${ }^{[18,25]}$ In addition, less than half of our sample of mothers $(42.1 \%)$ had a high intention to vaccinate their daughter against HPV. In contrast, $67 \%$ $97 \%$ of mothers from Korea, ${ }^{[30]}$ Indonesia, ${ }^{[31]}$ Kenya, ${ }^{[32]}$ Thailand $^{[33]}$ and New Zealand ${ }^{[34]}$ intended to vaccinate their daughters against HPV.

Although the HPV vaccines have been shown to prevent precancerous cervical lesions, ${ }^{[35]}$ the uptake rate in Taiwan has remained $<10 \%$. In fact, the high price was considered the greatest hurdle to vaccinating daughters, as previously reported. ${ }^{[18,27,31]}$ The percentage of Taiwanese mothers with high intention to vaccinate their daughters dropped from $88.9 \%$ to $69.8 \%$ when mothers were asked whether they were willing to pay to vaccinate their daughter if HPV vaccination were not covered by national health insurance or subsidized by the government, while the percentage of low-intention mothers dropped precipitously from $60.2 \%$ to $17.9 \%$. Although five county governments in Taiwan have started giving HPV vaccines to female teenage students free of charge, the remaining eight county governments still do not offer free vaccination. ${ }^{[12,19]}$ To increase the uptake of HPV vaccine by mothers of teenage girls in Taiwan, the government should increase its budget for cervical cancer prevention and subsidize HPV vaccination.

Another common reason for mothers' unwillingness to vaccinate daughters against HPV was mothers' not understanding the HPV vaccines. Our finding that high-intention mothers were more likely than low-intention mothers to believe that HPV vaccine is safe and effectively prevents cervical cancer suggest that disseminating HPV knowledge to mothers is important. We also found that doctors and nurses' recommendations played a significant role in mothers' decision 
to vaccinate their daughters against HPV, as reported. ${ }^{[22-25]}$ However, the previous reports focused on physicians' recommendations with little mention of nurses' role. Because nurses are the most visible and frontline personnel providing HPV knowledge to mothers, our results suggest that nurses should share HPV vaccine knowledge with mothers while they are waiting for treatment in gynecological clinics and explain the importance of vaccinating their adolescent daughters against HPV. Doing this will not only increase the uptake of daughters' HPV vaccination, but also that of mothers themselves. Another strategy to foster uptake is to encourage doctors and nurses to strongly recommend HPV vaccination to mothers of adolescent daughters. HPV knowledge could also be disseminated to mothers through newspapers, magazines or posters in private clinics and hospitals, consistent with previous studies. ${ }^{[23,24]}$ However, this strategy may not be suitable for low-intention mothers as they were less likely to be influenced by others' and media recommendations to vaccinate a daughter against HPV.

The results of our study are subject to some limitations. First, our results are based on data from a convenience sample of 511 mothers attending a regional hospital in central Taiwan. Thus, our findings may not generalize to all mothers in Taiwan. Second, the intention to adopt the HPV vaccine for daughters was examined among mothers only. Future studies should assess influences on Taiwanese fathers' intention for daughters' vaccination against HPV.

\section{Conclusions}

The findings of this study highlight that the cost of HPV vaccination is a major obstacle to Taiwanese mothers with low intention to have their daughters vaccinated against HPV. To increase the uptake of HPV vaccine in Taiwan, the vaccination cost should be covered by national health insurance or government subsidy. In addition, doctors and nurses should recommend HPV vaccination to high-intention mothers. These findings can be used by policy makers in Taiwan to plan appropriate activities and strategies to encourage mothers to have daughters receive the HPV vaccine, and in turn to increase the uptake of HPV vaccines for teenage girls.

\section{ACKNOWLEDGEMENTS}

The authors are grateful to all 511 participants for their time and effort contributed to this study.

\section{CONFLICTS OF INTEREST Disclosure}

The author(s) declared no potential conflicts of interest with respect to the research, authorship, and/or publication of this article.

\section{REFERENCES}

[1] World Health Organization. Human papillomavirus (HPV) and cervical cancer. Available from: http://www . who.int/mediacentr e/factsheets/fs380/en/. Accessed March, 2015

[2] Health Promotion Administration, Ministry of Health and Welfare. Available from: http://www.hpa.gov.tw/English/ClassShow . aspx?No=201401280006. Accessed Match 10, 2015. [in Chinese]

[3] Dochez C, Bogers JJ, Verhelst R, et al. HPV vaccines to prevent cervical cancer and genital warts: an update. Vaccine. 2014; 32(14): 1595-601. PMid: 24606637. http://dx.doi.org/10.1016/j.v accine.2013.10.081

[4] Centers for Disease Control and Prevention. Human papillomavirus (HPV). Available from: http://www.cdc.gov/hpv/vaccine.ht $\mathrm{ml}$. Accessed February 5, 2014.

[5] Markowitz LE, Dunne EF, Saraiya M, et al. Human papillomavirus vaccine: recommendations of the Advisory Committee on Immunization Practices (ACIP). MMWR Recomm Rep. 2014; 63: 1-30. PMid: 25167164. http://www.cdc.gov/mmwr/preview/mmwrh $\mathrm{tml} / \mathrm{rr} 6305 \mathrm{a} 1 . \mathrm{htm}$

[6] Centers for Disease Control and Prevention. FDA licensure of bivalent human papillomavirus vaccine (HPV2, Cervarix) for use in females and updated HPV vaccination recommendations from ACIP. Morbidity and Mortality Weekly Report. 2010; 59(20): 626-9. PMid: 20508593

[7] WHO. Human papillomavirus vaccines. WHO position paper. Weekly Epidemiological Record. 2014; 89: 465-92. PMid: 25346960.

[8] Lehtinen M, Paavonen J, Wheeler CM, et al. Overall efficacy of HPV-16/18 AS04-adjuvanted vaccine against grade 3 or greater cervical intraepithelial neoplasia: 4-year end-of-study analysis of the randomised, double-blind PATRICIA trial. The Lancet Oncology. 2012; 13(1): 89-99. http://dx.doi.org/10.1016/S1470-204 5 (11) $70286-8$

[9] GlaxoSmithKline Vaccine HPV-007 Study Group, Romanowski B, de Borba PC, et al. Sustained efficacy and immunogenicity of the human papillomavirus (HPV)-16/18 AS04-adjuvanted vaccine: analysis of a randomised placebo-controlled trial up to 6.4 years. Lancet. 2009; 374: 1975-85. http://dx.doi.org/10.1016/S0140-673 6(09) 61567-1

[10] Centers for Diseases Control and Prevention (CDC). Human Papillomavirus (HPV) Vaccine Safety. Available from: http://www.cdc. gov/vaccinesafety/vaccines/hpv-vaccine.html Accessed August 30, 2016

[11] Slade BA, Leidel L, Vellozzi C, et al. Postlicensure safety surveillance for quadrivalent human papillomavirus recombinant vaccine. Journal of the American Medical Association. 2009; 302(7): 750-7. PMid: 19690307. http://dx.doi.org/10.1001/jama.2009.1201

[12] Lee CC, Chen TS, Wu TZ, et al. A human papillomavirus public vaccination program in Taiwan: the Kinmen County experience. Journal of the Formosan Medical Association. 2012; 111(12): 682-5. PMid: 23265746. http://dx.doi.org/10.1016/j.jfma. 2012 .10 .004

[13] Chan MC, Chiu SK, Wu KC, et al. Human papillomavirus vaccination policy: a public health ethics perspective. Taiwan Journal of 
Public Health. 2013; 32: 309-19 [in Chinese].

[14] Demarteau N, Tang CH, Chen HC, et al. Cost-effectiveness analysis of the bivalent compared with the quadrivalent human papillomavirus vaccines in Taiwan. Value in Health. 2012; 15(5): 622-31. PMid: 22867770. http://dx.doi.org/10.1016/j.jval. 2012 .02 .012

[15] Pan F, Shu HG. Does parents' socio-economic status matter in intentions of vaccinating against human papillomavirus for adolescent daughters? African Health Sciences. 2015; 15(1): 25-32. PMid: 25834527. http://dx.doi.org/10.4314/ahs.v15i1.4

[16] Lee CC, Lee SH, Chen TS, et al. Factors associated with women intention of the human papillomavirus vaccination study in Kinmen. Health Promotion \& Health Education Journal. 2010; 30: 1-16 [in Chinese]. http://dx.doi.org/10.14367/kjhep.2013.30. 4.001

[17] Choi HC, Leung GM, Woo PP, et al. Acceptability and uptake of female adolescent HPV vaccination in Hong Kong: a survey of mothers and adolescents. Vaccine. 2013; 32(1): 78-84. PMid: 24188759. http://dx.doi.org/10.1016/j.vaccine.2013.10.068

[18] Mouallif M, Bowyer HL, Festali S, et al. Cervical cancer and HPV: awareness and vaccine acceptability among parents in Morocco. Vaccine. 2014; 32(3): 409-16. PMid: 24188754. http: //dx.doi.org/10.1016/j.vaccine.2013.10.069

[19] Health Promotion Administration, Ministry of Health and Welfare. HPV vaccine $\mathrm{Q} \& \mathrm{~A}$. Available from: http://www.hpa.gov.tw/BHPNet/Web/HealthTopic/TopicA rticle. aspx?No=201104150001\&parentid=201103150001. Accessed March 5, 2015. [in Chinese].

[20] Kahn JA, Ding L, Huang B, et al. Mothers' intention for their daughters and themselves to receive the human papillomavirus vaccine: a national study of nurses. Pediatrics. 2009; 123(6): 1439-45. PMid: 19482752. http://dx.doi.org/10.1542/peds. 2008-1536

[21] Griffioen AM, Glynn S, Mullins TK, et al. Perspectives on decision making about human papillomavirus vaccination among 11- to 12year-old girls and their mothers. Clinical pediatrics. 2012; 51(6): 560-8. PMid: 22589477. http://dx.doi.org/10.1177/00099 22812443732

[22] Reynolds D, O'Connell KA. Testing a model for parental acceptance of human papillomavirus vaccine in 9- to 18-year-old girls: a theoryguided study. Journal of Pediatric Nursing. 2012; 27(6): 614-25. PMid: 22020360. http://dx.doi.org/10.1016/j.pedn. 2011 .09 .005

[23] Dorell C, Yankey D, Kennedy A, et al. Factors that influence parental vaccination decisions for adolescents, 13 to 17 years old: National Immunization Survey-Teen, 2010. Clinical pediatrics. 2013; 52(2): 162-70. PMid: 23221308. http://dx.doi.org/10.1177/00099 22812468208

[24] Cates JR, Shafer A, Carpentier FD, et al. How parents hear about human papillomavirus vaccine: implications for uptake. The Journal of Adolescent Health. 2010; 47(3): 305-8. PMid: 20708571. http://dx.doi.org/10.1016/j.jadohealth.2010.04.003
[25] Dempsey AF, Abraham LM, Dalton V, et al. Understanding the reasons why mothers do or do not have their adolescent daughters vaccinated against human papillomavirus. Annals of Epidemiology. 2009; 19(8): 531-8. PMid: 19394865. http://dx.doi.org/10. 1016/j . annepidem. 2009.03.011

[26] Lu CY, Santosham M, APECI members. Survey of national immunization programs and vaccine coverage rates in Asia Pacific countries. Vaccine. 2012; 30(13): 2250-5. PMid: 22075085. http: //dx.doi.org/10.1016/j.vaccine.2011.10.070

[27] Sam IC, Wong LP, Rampal S, et al. Maternal acceptance of human papillomavirus vaccine in Malaysia. The Journal of Adolescent Health. 2009; 44(6): 610-2. PMid: 19465327. http://dx.doi.org/10. 1016/j.jadohealth.2008.11.014

[28] Rosenthal SL, Rupp R, Zimet GD, et al. Uptake of HPV vaccine: demographics, sexual history and values, parenting style, and vaccine attitudes. The Journal of Adolescent Health. 2008; 43(3): 239-45. PMid: 18710678 . http://dx.doi.org/10.1016/j.jadohealt h. 2008.06.009

[29] Askelson NM, Campo S, Lowe JB, et al. Using the theory of planned behavior to predict mothers' intentions to vaccinate their daughters against HPV. The Journal of School Nursing. 2010; 26(3): 194-202. PMid: 20335232. http://dx.doi.org/10.1177/10598405103 66022

[30] Oh JK, Lim MK, Yun EH, et al. Awareness of and attitude towards human papillomavirus infection and vaccination for cervical cancer prevention among adult males and females in Korea: a nationwide interview survey. Vaccine. 2010; 28(7): 1854-60. PMid: 20005860. http://dx.doi.org/10.1016/j.vaccine.2009.11.079

[31] Jaspers L, Budiningsih S, Wolterbeek R, et al. Parental acceptance of human papillomavirus (HPV) vaccination in Indonesia: a crosssectional study. Vaccine. 2011; 29(44): 7785-93. PMid: 21821079. http://dx.doi.org/10.1016/j.vaccine.2011.07.107

[32] Becker-Dreps S, Otieno WA, Brewer NT, et al. HPV vaccine acceptability among Kenyan women. Vaccine. 2010; 28(3): 4864-7. PMid: 20566394. http://dx.doi.org/10.1016/j.vaccine. 2 010.05 .034

[33] Kruiroongroj S, Chaikledkaew U, Thavorncharoensap M. Knowledge, acceptance, and willingness to pay for human papilloma virus (HPV) vaccination among female parents in Thailand. Asian Pacific Journal of Cancer Prevention. 2014; 15(13): 5469-74. PMid: 25041020 http://dx.doi.org/10.7314/APJCP. 2014.15.13.5469

[34] Rose SB, Lawton BA, Lanumata TS, et al. Predictors of intent to vaccinate against HPV/cervical cancer: a multi-ethnic survey of 769 parents in New Zealand. The New Zealand Medical Journal. 2012; 125(1350): 51-62. PMid: 22382257.

[35] Apter D, Wheeler CM, Paavonen J, et al. Efficacy of HPV-16/18 AS04-adjuvanted vaccine against cervical infection and precancer in young women: final event-driven analysis of the randomised, doubleblind PATRICIA trial. Clinical and Vaccine Immunology. 2015; 22(4): 361-73. PMid: 25651922. http://dx.doi.org/10.1128/CVI . 0 0591-14 